\title{
A within-subject comparison of different relaxation therapies in eliciting physiological and psychological changes in young women
}

\author{
Sarah Dib ${ }^{\text {Corresp., }}{ }^{\text {, }}$ Jonathan CK Wells ${ }^{1}$, Mary Fewtrell ${ }^{1}$ \\ ${ }^{1}$ UCL Great Ormond Street Institute of Child Health, University College London, London, United Kingdom \\ Corresponding Author: Sarah Dib \\ Email address: sarah.dib.15@ucl.ac.uk
}

Background. Stress reactivity can be different in women compared to men, which might consequently influence disease risk. Stress in women may also generate adverse physiological effects on their offspring during pregnancy or lactation. The objective of this study was to compare the effects of different relaxation interventions on physiological outcomes and perceived relaxation in healthy young women, to assist in identifying the most appropriate intervention(s) for use in a subsequent trial for mothers who deliver prematurely.

Methods. A within-subject study was conducted in 17 women of reproductive age comparing five different relaxation interventions (guided-imagery meditation audio [GIM], music listening [ML], relaxation lighting $[R L], G I M+R L, M L+R L$ ), with control (silence/sitting), assigned in random order over a 3-6 week period. Subjective feelings of relaxation (10-point scale), heart rate (HR), systolic and diastolic blood pressure (SBP, DBP), and fingertip temperature (FT) were measured before and after each technique

Results. All interventions significantly increased perceived relaxation and FT, while music also significantly reduced SBP $(p<0.05)$. Compared to control, HR significantly decreased following GIM (mean difference $=3.2 \mathrm{bpm}, \mathrm{p}<0.05$ ), and FT increased (mean difference $=2.2 \stackrel{\circ}{\circ}, p<0.05$ ) and SBP decreased (mean difference $=3.3 \mathrm{mmHg}, \mathrm{p}<0.01$ ) following $\mathrm{ML}$. GIM + RL followed by GIM were the most preferred interventions.

Conclusions. Based on preference, simplicity, and the physiological and psychological effects, GIM and $M L$ were identified as the most effective tools for reducing stress and improving relaxation. These techniques warrant further research in larger samples and other populations. 


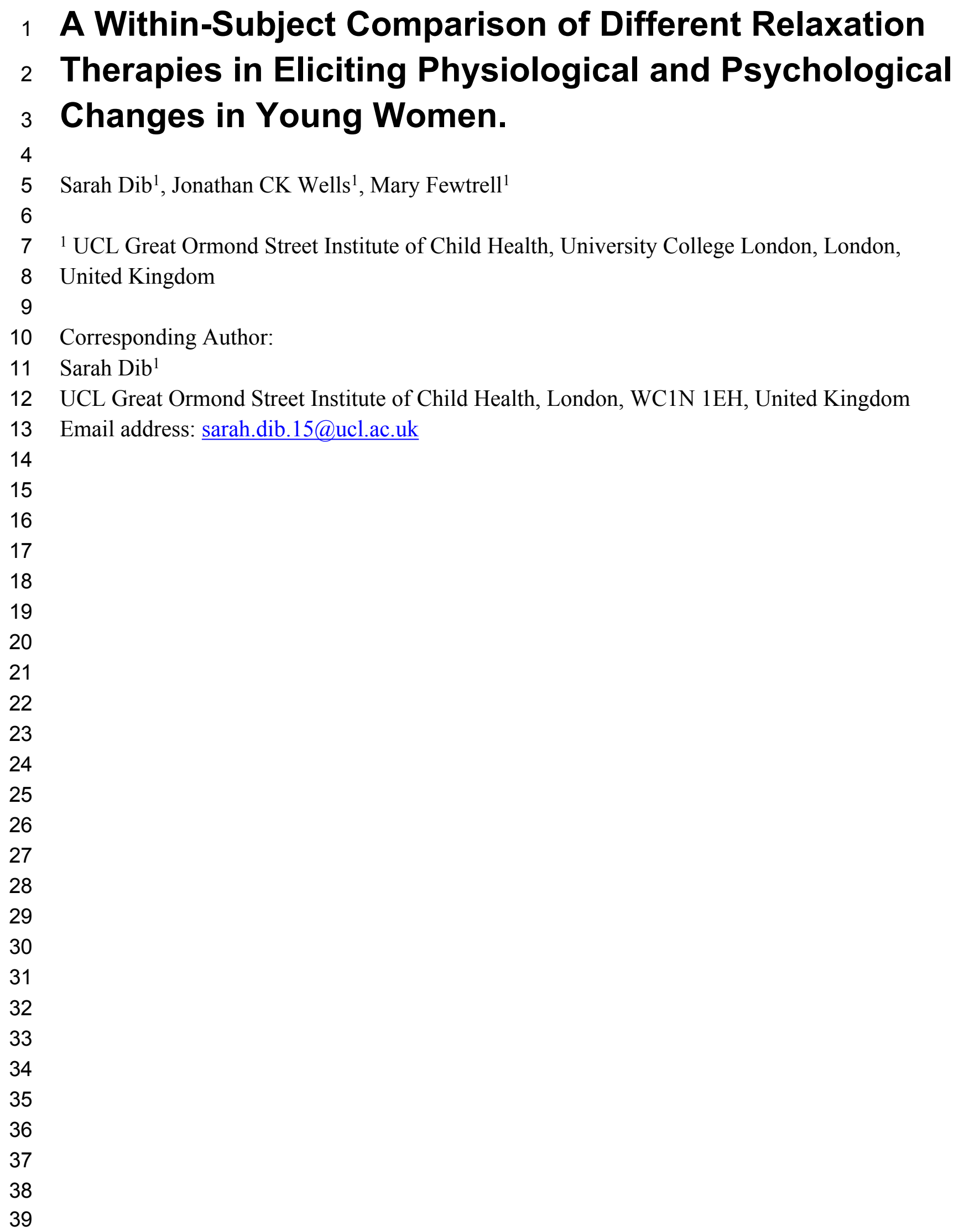




\section{Abstract}

41

42

43

44

45 46

48

49

50

51

52

53

54

55

56

57

58

59

60

61

62

66

67

68

69

70

66

Background. Stress reactivity can be different in women compared to men, which might consequently influence disease risk. Stress in women may also generate adverse physiological effects on their offspring during pregnancy or lactation. The objective of this study was to compare the effects of different relaxation interventions on physiological outcomes and perceived relaxation in healthy young women, to assist in identifying the most appropriate intervention(s) for use in a subsequent trial for mothers who deliver prematurely.

Methods. A within-subject study was conducted in 17 women of reproductive age comparing five different relaxation interventions (guided-imagery meditation audio [GIM], music listening [ML], relaxation lighting [RL], GIM+RL, ML+RL), with control (silence/sitting), assigned in random order over a 3-6 week period. Subjective feelings of relaxation (10-point scale), heart rate (HR), systolic and diastolic blood pressure (SBP, DBP), and fingertip temperature (FT) were measured before and after each technique

Results. All interventions significantly increased perceived relaxation and FT, while music also significantly reduced SBP $(\mathrm{p}<0.05)$. Compared to control, HR significantly decreased following GIM (mean difference $=3.2 \mathrm{bpm}, \mathrm{p}<0.05$ ), and FT increased (mean difference $=2.2{ }^{\circ} \mathrm{C}, \mathrm{p}<0.05$ ) and SBP decreased (mean difference $=3.3 \mathrm{mmHg}, \mathrm{p}<0.01$ ) following ML. GIM + RL followed by GIM were the most preferred interventions.

Conclusions. Based on preference, simplicity, and the physiological and psychological effects, GIM and ML were identified as the most effective tools for reducing stress and improving relaxation. These techniques warrant further research in larger samples and other populations.

7 


\section{Introduction}

72

73

74

75

76

77

78

79

80

81

82

83

84

85

86

87

88

89

90

91

92

93

94

95

96

97

98

99

100

101

102

103

104

105

106

107

108

109

110
The body responds to stressors, whether physiological or psychological, by mounting a "fight or flight" response characterized by increased sympathetic nervous system activation. This results in increased blood pressure (BP), heart rate (HR) and glucocorticoid production (Brotman et al. 2007). The stress response is assumed to have evolved to ensure the survival of the organism, and as the two sexes may face different sources of stress, the nature of the response may itself differ between males and females (Kajantie \& Phillips 2006). However, chronic stress or an exaggerated response can be harmful (McEwen 2008), and again could differ by gender.

Moreover, stress in women of reproductive age may have consequences not only for the individual, but potentially for her offspring. Maternal stress during pregnancy is associated with preterm delivery, low birth weight, and even adverse infant cognitive development (Beydoun \& Saftlas 2008; Bhang et al. 2016; Rondó et al. 2003; Talge et al. 2007). Similarly, during lactation, symptoms of maternal distress correlate negatively with breastfeeding success (Lau 2001), and potentially with infant growth and behaviour (Mohd Shukri et al. 2019). Interventions to reduce maternal stress thus have the potential to improve mother and infant outcomes, and to lower the risk of pregnancy and breastfeeding complications. However, the use of psychotherapy in this population is challenging due to stigma and financial and logistical barriers (Goodman 2009). This suggests a need for alternative simple therapies.

Relaxation techniques such as music listening (Knight \& Rickard Ph 2001), relaxation training (Bastani et al. 2005) and mindfulness (Vieten \& Astin 2008) are reported to reduce stress and increase relaxation. Some studies have also described a reduction in stress hormones, such as cortisol (Chellew et al. 2015; Dolbier \& Rush 2012), and in symptoms of anxiety and depression (Manzoni et al. 2008). Light therapy might also reduce stress by stimulating the suprachiasmatic nucleus in the hypothalamus and modulating the release of cortisol and adrenocorticotrophic hormone (Pail et al. 2011). Studies have shown a reduction in HR, BP, oxygen consumption and carbon dioxide production following exposure to blue light (Cajochen et al. 2005; Litscher et al. 2013). Bright Light Therapy, which utilises blue light of high intensity ( 7000-10000 lux), has been consistently found in several RCTs to influence mood disorders such as seasonal affective disorder (Lam et al. 2006; Strong et al. 2009) and non-seasonal depression (Lam et al. 2016; Wirz-Justice et al. 2011). Colourful ambient lighting has also been used in medical settings and was shown to improve patient satisfaction and lower pain ratings (Robinson \& Green 2015).

Different stress markers have been used to measure the stress response. Psychometric tools, such as the Visual Analogue Scale (VAS) for Stress or Perceived Stress Scale, were developed and widely used by the medical community to assess cognitive changes due to stress. However, these tools are subjective, and it is not known whether they correlate with physiological markers of stress, especially acute stress. Moreover, VAS has shown good within-subject reliability and 
111 validity, but not between participants (Stubbs et al. 2000). Objective markers that assess the 112 hormonal response to stress are also used; cortisol being the most commonly measured. The 113 disadvantages of using these markers include the relative invasiveness, cost of analysis and 114 difficulty of performing measurements in daily life. Other objective markers of stress include 115 physiological measurements such as heart rate, blood pressure, skin conductance, skin 116 temperature and respiratory rate. Currently, there is no general consensus on the optimal way to 117 measure stress. Therefore, in this study, we selected the most feasible, non-invasive 118 physiological and psychological markers which could be used in daily life to assess 119 stress/relaxation.

120

It is unknown whether relaxation techniques differ in their ability to reduce stress measured by physiological and psychological parameters. Moreover, most studies test the effectiveness of relaxation techniques in populations diagnosed with mood disorders, and it is unclear whether similar physiological changes are observed in healthy or at risk individuals. Lastly, the relation between perceived relaxation/stress and physical relaxation measured objectively is unclear.

In this study we compared the effects of five simple relaxation interventions on physiological markers and perception of stress in women of reproductive age. Our aim was to establish the most effective technique(s) for use in this population, but also to identify the most promising interventions that are feasible for use in a future study investigating stress reduction in women who deliver prematurely.

\section{Materials \& Methods}

\section{Study Design}

136

This was a within-subject study, where each participant received five different relaxation techniques and one silence/sitting control state in random order over a 3-6 week period, to minimize carry over effects (Figure 1). The primary outcomes - perceived relaxation (PR), HR, BP and fingertip temperature (FT) - were measured at baseline prior to each intervention and post-intervention. The participants were reimbursed at the end of the study for their time. The protocol and procedures were reviewed and ethically approved by the UCL Research Ethics Committee (ref 12521/001) and the trial was registered at Clinicaltrials.gov [NCT03592147].

Participants were recruited by advertisement using flyers displayed at University College London, UK. Interested women contacted the researchers and received information about the study. After checking eligibility and obtaining written informed consent, the participants were enrolled in the study and assigned a random order of interventions generated using a computerised random number generator. 
150 Each participant was allocated one or two time slots per week (based on their preference and

151

152

153

154

155

156

157

158

159

160

161

162

163

164

165

166

167

168

169

170

171

172

173

174

175

176

177

178

179

180

181

182

183

184

185

186

187

188

189 availability) to undergo the five relaxation interventions (guided-imagery meditation (GIM) audio, music listening (ML), "relaxation" lighting (RL), combination of RL and GIM, and a combination of RL and ML) and control sessions. All sessions took place in a private, quiet room with controlled lighting and room temperature. To reduce variability due to circadian rhythm effects on hormones and mood, all sessions were scheduled between 9AM and 1PM, whenever possible. The participants were asked to leave their belongings including any electronic devices or books outside the room

Baseline information was collected, including date of birth, ethnicity, occupation, history of treatment of psychiatric illness, and if currently pregnant or breastfeeding. The Perceived Stress Scale (PSS), a 10-item instrument that measures the extent to which one's life is perceived as stressful or uncontrollable and overwhelming over the last month (Cohen et al. 1983), was used to assess stress levels at baseline and at the end of the study.

\section{Eligibility Criteria for Participants}

Adult women of reproductive age (18-45 years), who were fluent in English, were eligible to participate. The exclusion criteria included smokers, having any recent surgery or injury, and/or having any condition that may affect BP, HR, or energy expenditure, such as hypertension or hypothyroidism.

\section{Interventions}

\section{Guided Imagery Meditation Tape}

Each participant was played, using headphones, a modified version of a GIM tape (Menelli 2004). It has been previously successfully used in three randomized controlled trials for breastfeeding mothers (Feher et al. 1989; Keith et al. 2012; Mohd Shukri et al. 2019). The modified version excluded parts pertinent to breastfeeding to adapt it to our sample and was approximately 7 minutes in duration.

\section{Music Listening}

Research suggests that to enhance the effects of music for relaxation, the music must be individualized based on the preferences of the participants. Therefore, we offered the women the option of selecting one of the following music categories: New age/guitar solo ("Internal Flight"), classical ("Pavane pour une Infante Défunte in G Major M.19"; "Gnossienne n ${ }^{\circ}$ 5"), and oriental ("Way to Heaven"; "Dune"). The songs were selected based on criteria established in a previous study to induce relaxation, including slow tempo below or at resting $\operatorname{HR}(<72 \mathrm{bpm})$, repetitive rhythm, predictable dynamics, pleasant harmonies, and tonal qualities that include strings, flute or piano (Knight \& Rickard Ph 2001; Robb 2000). All songs were also modified in length to be approximately 7 minutes in duration and played through headphones. 
190

191

192

193

194

195

196

197

198

199

200

201

202

203

204

205

206

207

208

209

210

211

212

213

214

215

216

217

218

219

220

221

222

223

224

225

226

227

228

229

\section{Relaxation Lighting}

In a study in Singapore, cool blue light had the most relaxing effect, according to patient and staff feedback, whereas in Germany, warm orange light was preferred (Philips, 2017, pers. comm.). Therefore, we asked the participants to select either the orange ("Relax" setting) or blue ("Energise" setting) lighting using the Philips Hue White and Colour Ambiance system (Philips, Netherlands). The intensity of the light was fixed to control for that measure. RL also lasted for 7 minutes in duration.

Combination Interventions (Meditation + Relaxation Lighting; Music Listening + Relaxation Lighting):

GIM and ML were combined with RL to investigate whether they had a synergistic effect on relaxation.

\section{Control/Silence:}

The participants were asked to relax for a duration of 7 minutes, with no explicit advice given. Lighting was adjusted to a specific intensity and colour (basic yellow light) as was used in the ML and GIM interventions.

\section{Outcome Measures}

The primary outcomes of this study were the mean changes in PR, HR, systolic blood pressure (SBP), diastolic blood pressure (DBP) and FT. PR was assessed using a visual analogue scale, which is a $10 \mathrm{~cm}$ horizontal line spanning from the minimum to the maximum of the variable measured. The minimum (left) represents "completely unrelaxed" and the maximum (right) "completely relaxed". The women marked a point on the scale to indicate their feelings of relaxation prior to and after each treatment. The distance between the mark and the minimum point was measured in centimetres (two decimal points) and the difference between pre- and post-intervention values were analysed. After the participant rested for 5 minutes, HR and BP were also measured pre- and post-relaxation technique using a digital sphygmomanometer (Omron M6, Japan). Lastly, a non-contact digital thermometer (Omron Gentle Temp 720, Japan) was used to measure FT as an indication of sympathetic nervous system activation. These measurements were taken three times and the mean was used for analysis. At the end of the study, the women were asked to rank the relaxation interventions in order of preference, and were given the option to make comments about the different techniques.

\section{Sample Size}

In a previous study investigating the effect of audio-visual imagery on patient anxiety and physiological measurements, including HR, a sample of 51 patients was able to demonstrate a significant reduction in HR (mean change $(Z)=-0.75, \mathrm{SD}=1.00 ; \mathrm{p}=0.01$ ) (Vogel et al. 2012). Using a within-subject design, a sample of 15 participants would be able to detect a 0.75 mean difference in HR following relaxation significant at $5 \%$ with a power of $80 \%$. 
230

231

232

233

234

235

236

237

238

239

240

241

\section{Results}

\section{Descriptive data}

244

245

246

247

248

249

250

251

252

253

254

255

256

257

258

259

260

261

262

263

264

265

266

267

268

269

\section{Statistical Analysis}

\section{Intervention results} Table 3.

Data were analysed using SPSS 21.0. First, the pre- and post-test changes were assessed using a paired t-test to test the effectiveness of each intervention and control. Then, to compare the interventions to control, the change in each primary outcome from pre- to post-intervention was compared to the change from pre- to post-control using a paired t-test. Variations in baseline measurements prior to each intervention may influence the observed response to each intervention. To account for this, we calculated the unstandardized residuals and repeated the same analysis. Lastly, associations between the physiological (BP, HR, FT) and psychological (PR, perceived stress) measurements were explored using Pearson's and Spearman's correlation tests, as appropriate. P-values $<0.05$ were considered statistically significant.

\section{The descriptive characteristics of the participants are presented in Table 1. Seventeen women} with mean age 30.3 years $( \pm 6.2)$ participated. Nine participants reported regularly using a form of relaxation such as meditation, music, and yoga, while the eight others did not seek such techniques. At baseline, the average score on the PSS was $15.8 \pm 5.2$. The majority $(71 \%)$ of the participants experienced moderate stress levels (14-26 points) and the rest low stress (Table 1). There were no significant differences in physiological parameters (HR, BP, FT) or PR at baseline between low and moderately stressed participants (data not shown).

Changes in Outcomes during Interventions:

Pre to post-test changes in PR, SBP, DBP, HR and FT were compared to test the effectiveness of each intervention and control. As shown in Table 2, PR increased significantly following all interventions and control. All interventions significantly increased FT but this was not seen during the control session. Music was the only intervention to produce significant reductions in $\operatorname{SBP}(-4.1 \pm 5.0 \mathrm{mmHg})$.

\section{Comparison with Control}

Mean changes in PR, SBP, DBP, HR, and FT following each intervention were compared with control to ascertain the relative effectiveness of the interventions (Figure 2). Compared with control, HR significantly decreased with GIM (mean difference $=3.2 \mathrm{bpm}, \mathrm{p}=0.015$ ). All interventions reduced SBP and increased FT; however, compared to control, the change was only significant with the music intervention (mean difference $=-3.3 \mathrm{mmHg}, \mathrm{p}=0.049$ and $2.2^{\circ} \mathrm{C}$, $\mathrm{p}<0.01$, respectively). Change in PR (Figure 3) was significantly higher than control following music, GIM, GIM + RL, and ML+RL $(\mathrm{p}<0.05)$. Mean (SD) and effect sizes are presented in 
270

271

272

273

274

275

276

277

278

279

280

281

282

283

284

285

286

287

288

289

290

291

292

293

294

295

296

297

298

299

300

301

302

303

304

305

306

307

308

309

Comparison with Control (Controlling for Baseline Measurements):

Using the unstandardized residuals, the previous results were unchanged; compared to control, HR decreased significantly more following GIM, while SBP was reduced and FT increased significantly more following ML.

\section{Preferences}

Forty-three percent of the participants selected GIM $+\mathrm{RL}$ as their most preferred intervention, followed by GIM (24.1\%) then ML (14.3\%) and ML + RL (14.3\%).

\section{Perceived Stress:}

At the end of the study, average PSS score $(15.9 \pm 5.6)$ was not significantly different from PSS at baseline $(15.8 \pm 5.2)$.

\section{Perceived vs Physiological Relaxation/Stress:}

No association was found between change (from pre to post intervention) in PR and change in SBP, DBP, HR, and FT. However, in the cases where change in FT was greater than $1.5^{\circ} \mathrm{C}$, increases in PR (measured using VAS) and FT were significantly correlated ( $r=0.364, p<0.05$ and when $\left.>2{ }^{\circ} \mathrm{C}, \mathrm{r}=0.470, \mathrm{p}<0.01\right)$.

Higher perceived stress, measured by PSS at baseline, was associated with a lower reduction in SBP following music ( $r=0.615, p=0.009)$ and GIM $+R L(r=0.495, p=0.043)$. Change in SBP in participants with low vs high PSS was $-7.9 \pm 4.1 \mathrm{mmHg}$ and $-2.5 \pm 4.7 \mathrm{mmHg}$ following music and $-4.2 \pm 3.1$ and $-0.8 \pm 5.9$ following GIM + RL. This indicates that subjects experiencing lower stress levels in the previous month had greater reductions in SBP following relaxation interventions. Similarly, a lower reduction in SBP following music $(\mathrm{r}=0.556, \mathrm{p}=0.02)$ and a lower increase in FT following silence/control $(\mathrm{r}=-0.643, \mathrm{p}=0.005)$ was associated with higher perceived stress at the end of the 3-6 week study. Participants with low vs high PSS at the end of the study had a mean change in SBP equivalent to $-6.8 \pm 5.8 \mathrm{mmHg}$ and $-2.2 \pm 3.6 \mathrm{mmHg}$ following ML, and a mean change in FT equal to $3.4 \pm 2.8^{\circ} \mathrm{C}$ and $-0.2 \pm 1.7{ }^{\circ} \mathrm{C}$ following control/silence.

\section{Discussion}

Previous studies have investigated light therapies, music listening, or meditation individually in relation to subjective assessment of anxiety, stress or depression. Only a few studied the effects of relaxation techniques on measurable physiological changes such as HR, BP, and FT.

Moreover, many previous studies have focused on the short-term effects of stress interventions in special populations. Our study differs from previous studies as it assesses the short-term effects of different relaxation interventions in healthy participants. 
310 All interventions and control significantly increased PR. Moreover, all interventions, but not the 311 control, significantly increased FT while music significantly reduced SBP. When compared to 312 control, however, GIM was the most effective intervention for increasing subjective feeling of 313 relaxation and reducing HR. ML also significantly increased PR and FT, and decreased SBP 314 compared to control.

315

316 The results are consistent with previous studies that showed any relaxation technique is capable

317 of producing significant relaxation responses (Regehr et al. 2013). However, the advantage of the 318 current study is the within-subject design that includes a control setting, which limits subject and environment variations. Comparing each intervention to the control demonstrated that GIM was

320

321

322

323

324

325

326

327 328

329

330

331

332

333

334

335

336

337

338

339

340

341

342

343

344

345

346

347

348

349 the most effective overall when considering the physiological and psychological relaxation effects and preferences. ML produced a significant increase in FT, an indication of sympathetic nervous system stimulation, and a significant decrease in SBP. It is important to note that, on average, participants had lower baseline temperatures prior to the ML intervention. Having lower FT at baseline was associated with greater increases, whereas participants with higher FT at baseline had less potential for significant change. Thus, we controlled for the differences in baseline measurements by calculating the unstudentized residuals; however, the results remained unchanged indicating that music had an effect on FT and SBP regardless of the baseline value.

A similar within-subject study comparing the five interventions was recently conducted in Beijing, China, in mothers who were breastfeeding their healthy term infant (Yu et al. 2018). GIM was identified as the most effective relaxation intervention as it significantly reduced HR and increased PR compared to control, as seen in our study. Moreover, all treatments significantly increased PR. However, GIM also significantly decreased BP, and all treatments produced significant increases in FT and some reductions in BP, which was not observed in our study. The discrepancy in results might be due to the difference in characteristics of the two populations. Breastfeeding is associated with increased parasympathetic nervous system modulation and an attenuated stress response. Lactating mothers may also experience lower perceived stress levels, which might improve the response to relaxation interventions. The differences might also reflect cultural factors. The use of complementary and alternative medicine is more common in China than in the UK (Dixon 2008), and is especially prevalent among lactating mothers (Sim et al. 2013). Breastfeeding participants in China might have been more receptive to the relaxation treatments than our sample of young women living in the UK, which might have enhanced their response to the interventions.

Interestingly, we found no association between the change in PR measured using VAS and the change in physiological measures (HR, BP, and FT). The discrepancy might be explained by the fact that subjective measurements such as the PSS and VAS are susceptible to recall bias, attention bias, and self-deception (Goyal et al. 2016). Conversely, objective measures rule out the possibility of these, but can be prone to measurement error and confounding effects of 
350

351

352

353

354

355

356

357

358

359

360

361

362

363

364

365

366

367

368

369

370

371

372

373

374

375

376

377

378

379

380

381

382

383

384

385

386

387

388

389

variables such as physical activity. The lack of association might be also due to the chemical basis by which the relaxation interventions were able to produce changes in physiological measurements. For example, oxytocin is known to produce anti-stress effects, which is evident in pregnant and lactating women who experience an attenuated stress response due to the increased levels of oxytocin (Moberg \& Prime 2013). Oxytocin has also been recognised as a cardiovascular hormone that can reduce BP and slow HR (Gutkowska et al. 2014). A recent study looking at the effect of relaxing (slow-tempo) and exciting (fast-tempo) music on salivary oxytocin and cortisol demonstrated that listening to relaxing music resulted in a significant increase in oxytocin (Ooishi et al. 2017). They also investigated the association between change in oxytocin and change in both HR and self-reported emotions (arousal). The ratio of increase in oxytocin was significantly related to the ratio of decrease in HR; however, oxytocin was not related to self-reported emotions. These results are consistent with our study, where the relaxation interventions elicited a physiological response which was not correlated with psychological/perceived relaxation. Further research is required to investigate the association between perceived, physiological, and biochemical mediators of relaxation.

By contrast, higher perceived stress measured by PSS was associated with lower changes in SBP and FT following certain interventions. Additionally, there was no significant difference in physiological measures between low and moderately stressed groups. Similar to our study, others have shown that the perception of stress is closely related to physiological measurements and might blunt cardiac reactivity to stressors (Gartland et al. 2014; Ginty \& Conklin 2011). Therefore, our results might indicate that, even though the participants experienced an increase in their PR measured by VAS following the different relaxation interventions, higher general perceived stress (measured using the PSS) might attenuate the more immediate physiological response to the interventions.

The majority of participants selected GIM + RL as their most preferred intervention, with the second most preferred options being GIM then ML. Physiologically, however, adding RL to GIM did not produce any additive effect, and it reduced the effect of GIM on HR and PR. GIM requires participants to follow verbal instructions, including concentrating on breathing and keeping eyes closed at certain time points. Conversely with the RL, participants might be inclined to focus on keeping their eyes open to benefit from the light. This might create sensory overload and counteract the relaxation response.

The strengths of the present study include the within-subject study design that also includes a control state. The main limitation of the study is the short duration of each intervention (6-7 minutes). Relaxation techniques such as lighting might require longer and repeated exposure to produce a relaxation response. However, we demonstrated that even with this short time period, some relaxation interventions could induce a response; we predict that prolonged and consistent use of those techniques might have further benefits. Further studies including a larger sample 
390

391

392

393

394

395

396

397

398

399

400

401

402

403

404

405

406

407

408

409

410

411

412

413

414

415

416

417

418

419

420

421

422

423

424

425

426

427

428

429

430

431

should investigate this. Another limitation was that we did not collect information on the phase of menstrual cycle or hormonal contraceptive use, thus we could not assess its influence on the reactivity to relaxation interventions. Lastly, we did not adjust the p-value for multiple testing which should be considered when interpreting the results.

\section{Conclusions}

In young women of reproductive age we were able to experimentally demonstrate that preferencebased ML and GIM were the most effective interventions for reducing stress when compared to the control setting. These findings are informative in defining the most appropriate relaxation interventions for use in future studies aimed at stress reduction in women during pregnancy and lactation; by diverting the use of energy from stress and increasing energy investment in the infant, such interventions have the potential to improve pregnancy and breastfeeding outcomes. We found no association between perceived and physiological indicators of relaxation (HR, BP, and FT). Future studies should investigate this further, including biochemical indices of stress/relaxation, such as cortisol and oxytocin. Establishing associations between different indicators of stress/relaxation and clinical outcomes is also important in order to define the most appropriate outcome measures for use in studies testing relaxation interventions.

\section{References}

Bastani F, Hidarnia A, Kazemnejad A, Vafaei M, and Kashanian M. 2005. A randomized controlled trial of the effects of applied relaxation training on reducing anxiety and perceived stress in pregnant women. Journal of midwifery \& women's health 50:e36-e40.

Beydoun H, and Saftlas AF. 2008. Physical and mental health outcomes of prenatal maternal stress in human and animal studies: a review of recent evidence. Paediatr Perinat Epidemiol 22:438-466. 10.1111/j.1365-3016.2008.00951.x

Bhang S-Y, Ha E, Park H, Ha M, Hong Y-C, Kim B-N, Lee S-J, Lee KY, Kim JH, Jeong J, Jeong KS, Lee B, and Kim Y. 2016. Maternal Stress and Depressive Symptoms and Infant Development at Six Months: the Mothers and Children's Environmental Health (MOCEH) Prospective Study. Journal of Korean medical science 31:843-851. $10.3346 / \mathrm{jkms} .2016 .31 .6 .843$

Brotman DJ, Golden SH, and Wittstein IS. 2007. The cardiovascular toll of stress. The lancet 370:1089-1100.

Cajochen C, Münch M, Kobialka S, Kräuchi K, Steiner R, Oelhafen P, Orgül S, and Wirz-Justice A. 2005. High Sensitivity of Human Melatonin, Alertness, Thermoregulation, and Heart Rate to Short Wavelength Light. The Journal of Clinical Endocrinology \& Metabolism 90:1311-1316. 10.1210/jc.2004-0957

Chellew K, Evans P, Fornes-Vives J, Perez G, and Garcia-Banda G. 2015. The effect of progressive muscle relaxation on daily cortisol secretion. Stress 18:538-544. $10.3109 / 10253890.2015 .1053454$ 
432 Cohen S, Kamarck T, and Mermelstein R. 1983. A Global Measure of Perceived Stress. Journal

433

434

435

436

437

438

439

440

441

442

443

444

445

446

447

448

449

450

451

452

453

454

455

456

457

458

459

460

461

462

463

464

465

466

467

468

469

470

471

472

473

474

475

476

477

of Health and Social Behavior 24:385-396. 10.2307/2136404

Dixon A. 2008. Regulating complementary medical practitioners: case studies. King's Fund.

Dolbier CL, and Rush TE. 2012. Efficacy of abbreviated progressive muscle relaxation in a highstress college sample. International Journal of Stress Management 19:48-68. $10.1037 / \mathrm{a} 0027326$

Feher SDK, Berger LR, Johnson JD, and Wilde JB. 1989. Increasing Breast Milk Production for Premature Infants With a Relaxation/Imagery Audiotape. Pediatrics 83.

Gartland N, O'Connor DB, Lawton R, and Bristow M. 2014. Exploring day-to-day dynamics of daily stressor appraisals, physical symptoms and the cortisol awakening response. Psychoneuroendocrinology 50:130-138. 10.1016/j.psyneuen.2014.08.006

Ginty AT, and Conklin SM. 2011. High perceived stress in relation to life events is associated with blunted cardiac reactivity. Biol Psychol 86:383-385. 10.1016/j.biopsycho.2011.01.002

Goodman JH. 2009. Women's attitudes, preferences, and perceived barriers to treatment for perinatal depression. Birth 36:60-69.

Goyal A, Singh S, Vir D, and Pershad D. 2016. Automation of stress recognition using subjective or objective measures. Psychological Studies 61:348-364.

Gutkowska J, Jankowski M, and Antunes-Rodrigues J. 2014. The role of oxytocin in cardiovascular regulation. Brazilian journal of medical and biological research $=$ Revista brasileira de pesquisas medicas e biologicas 47:206-214. 10.1590/1414-431X20133309

Kajantie E, and Phillips DI. 2006. The effects of sex and hormonal status on the physiological response to acute psychosocial stress. Psychoneuroendocrinology 31:151-178.

Keith DR, Weaver BS, and Vogel RL. 2012. The Effect of Music-Based Listening Interventions on the Volume, Fat Content, and Caloric Content of Breast Milk-Produced by Mothers of Premature and Critically Ill Infants. Adv Neonatal Care 12. 10.1097/ANC.0b013e31824d9842

Knight WE, and Rickard Ph DN. 2001. Relaxing music prevents stress-induced increases in subjective anxiety, systolic blood pressure, and heart rate in healthy males and females. $J$ Music Ther 38:254-272.

Lam RW, Levitt AJ, Levitan RD, Enns MW, Morehouse R, Michalak EE, and Tam EM. 2006. The Can-SAD study: a randomized controlled trial of the effectiveness of light therapy and fluoxetine in patients with winter seasonal affective disorder. Am J Psychiatry 163:805-812. 10.1176/ajp.2006.163.5.805

Lam RW, Levitt AJ, Levitan RD, Michalak EE, Cheung AH, Morehouse R, Ramasubbu R, Yatham LN, and Tam EM. 2016. Efficacy of Bright Light Treatment, Fluoxetine, and the Combination in Patients With Nonseasonal Major Depressive Disorder: A Randomized Clinical Trial. JAMA Psychiatry 73:56-63. 10.1001/jamapsychiatry.2015.2235

Lau C. 2001. Effects of Stress on Lactation. Pediatr Clin N Am 48. 10.1016/s00313955(05)70296-0

Litscher D, Wang L, Gaischek I, and Litscher G. 2013. The Influence of New Colored Light Stimulation Methods on Heart Rate Variability, Temperature, and Well-Being: Results of a Pilot Study in Humans. Evidence-Based Complementary and Altern Med 1-7.

Manzoni GM, Pagnini F, Castelnuovo G, and Molinari E. 2008. Relaxation training for anxiety: a ten-years systematic review with meta-analysis. BMC Psychiatry 8:41. 10.1186/1471$244 \mathrm{x}-8-41$

Peer] reviewing PDF | (2019:09:41224:1:1:NEW 17 Apr 2020) 
478

479

480

481

482

483

484

485

486

487

488

489

490

491

492

493

494

495

496

497

498

499

500

501

502

503

504

505

506

507

508

509

510

511

512

513

514

515

516

517

518

519

520

521

522

523

McEwen BS. 2008. Central effects of stress hormones in health and disease: Understanding the protective and damaging effects of stress and stress mediators. Eur J Pharmacol 583:174185. 10.1016/j.ejphar.2007.11.071

Menelli S. 2004. Breastfeeding Meditation. White Heart Publishing.

Moberg KU, and Prime DK. 2013. Oxytocin effects in mothers and infants during breastfeeding. Infant 9:201-206.

Mohd Shukri NH, Wells J, Eaton S, Mukhtar F, Petelin A, Jenko-Praznikar Z, and Fewtrell M. 2019. Randomized controlled trial investigating the effects of a breastfeeding relaxation intervention on maternal psychological state, breast milk outcomes, and infant behavior and growth. Am J Clin Nutr. 10.1093/ajen/nqz033

Ooishi Y, Mukai H, Watanabe K, Kawato S, and Kashino M. 2017. Increase in salivary oxytocin and decrease in salivary cortisol after listening to relaxing slow-tempo and exciting fasttempo music. PloS one 12:e0189075.

Pail G, Huf W, Pjrek E, Winkler D, Willeit M, Praschak-Rieder N, and Kasper S. 2011. Brightlight therapy in the treatment of mood disorders. Neuropsychobiology 64:152-162.

Regehr C, Glancy D, and Pitts A. 2013. Interventions to reduce stress in university students: A review and meta-analysis. Journal of Affective Disorders 148:1-11. https://doi.org/10.1016/j.jad.2012.11.026

Robb SL. 2000. Music assisted progressive muscle relaxation, progressive muscle relaxation, music listening, and silence: a comparison of relaxation techniques. J Music Ther 37:221.

Robinson PS, and Green J. 2015. Ambient versus traditional environment in pediatric emergency department. Herd 8:71-80. 10.1177/1937586714566412

Rondó PHC, Ferreira RF, Nogueira F, Ribeiro MCN, Lobert H, and Artes R. 2003. Maternal psychological stress and distress as predictors of low birth weight, prematurity and intrauterine growth retardation. European Journal of Clinical Nutrition 57:266-272. 10.1038/sj.ejcn.1601526

Sim TF, Sherriff J, Hattingh HL, Parsons R, and Tee LB. 2013. The use of herbal medicines during breastfeeding: a population-based survey in Western Australia. BMC Complementary and Alternative Medicine 13:317. 10.1186/1472-6882-13-317

Strong RE, Marchant BK, Reimherr FW, Williams E, Soni P, and Mestas R. 2009. Narrow-band blue-light treatment of seasonal affective disorder in adults and the influence of additional nonseasonal symptoms. Depress Anxiety 26:273-278. 10.1002/da.20538

Stubbs RJ, Hughes DA, Johnstone AM, Rowley E, Reid C, Elia M, Stratton R, Delargy H, King N, Blundell JE. 2000. The use of visual analogue scales to assess motivation to eat in human subjects: a review of their reliability and validity with an evaluation of new handheld computerized systems for temporal tracking of appetite ratings. British Journal of Nutrition 84(4):405-15.

Talge NM, Neal C, and Glover V. 2007. Antenatal maternal stress and long-term effects on child neurodevelopment: how and why? J Child Psychol Psychiatry 48:245-261. 10.1111/j.1469-7610.2006.01714.x

Vieten C, and Astin J. 2008. Effects of a mindfulness-based intervention during pregnancy on prenatal stress and mood: results of a pilot study. Archives of Women's Mental Health 11:67-74. 10.1007/s00737-008-0214-3

Vogel WV, Valdes Olmos RA, Tijs TJ, Gillies MF, van Elswijk G, and Vogt J. 2012. Intervention to lower anxiety of $18 \mathrm{~F}-\mathrm{FDG}$ PET/CT patients by use of audiovisual

PeerJ reviewing PDF | (2019:09:41224:1:1:NEW 17 Apr 2020) 
524 imagery during the uptake phase before imaging. J Nucl Med Technol 40:92-98.

$525 \quad 10.2967 /$ jnmt.111.097964

526 Wirz-Justice A, Bader A, Frisch U, Stieglitz RD, Alder J, Bitzer J, Hosli I, Jazbec S, Benedetti F, 527

528

529

530

531

532 Terman M, Wisner KL, and Riecher-Rossler A. 2011. A randomized, double-blind, placebo-controlled study of light therapy for antepartum depression. J Clin Psychiatry 72:986-993. 10.4088/JCP.10m06188blu

Yu J, Wells J, Wei Z, and Fewtrell M. 2018. Randomized Trial Comparing the Physiological and Psychological Effects of Different Relaxation Interventions in Chinese Women

533 Breastfeeding Their Healthy Term Infant. Breastfeeding Medicine. 
Table $\mathbf{1}$ (on next page)

Descriptive characteristics of the sample $(\mathrm{N}=17)$ 


\begin{tabular}{|c|c|}
\hline Characteristics & $\mathrm{n}(\%)$ \\
\hline \multicolumn{2}{|l|}{ Age (years) } \\
\hline $18-24$ & $3(17.6)$ \\
\hline $25-29$ & $5(29.4)$ \\
\hline $30-34$ & $4(23.5)$ \\
\hline 34-39 & $3(17.6)$ \\
\hline $40-45$ & $2(11.8)$ \\
\hline \multicolumn{2}{|l|}{ Ethnicity } \\
\hline White & $9(52.9)$ \\
\hline Asian & $5(29.4)$ \\
\hline Arab & $2(11.8)$ \\
\hline Other & $1(5.9)$ \\
\hline \multicolumn{2}{|l|}{ Employment Status } \\
\hline Full-time & $8(47.1)$ \\
\hline Part-time & $2(11.8)$ \\
\hline Student & $6(35.3)$ \\
\hline Unemployed & $1(5.9)$ \\
\hline \multicolumn{2}{|l|}{ Perceived Stress (Baseline) } \\
\hline Low Stress & $5(29.4 \%)$ \\
\hline Moderate Stress & $12(70.6 \%)$ \\
\hline
\end{tabular}


8

9

10

11

12

13

14 


\section{Table 2 (on next page)}

Mean changes in perceived relaxation, blood pressure, heart rate and fingertip temperature during interventions.

${ }^{*} \mathrm{p}<0.05,{ }^{* *} \mathrm{p}<0.01 ; \mathrm{GIM}$ : Guided-imagery Meditation, RL: Relaxation Lighting 
1 Table 2. Mean Changes in Perceived Relaxation, Blood Pressure, Heart Rate and Fingertip Temperature during Interventions

\begin{tabular}{|c|c|c|c|c|c|c|c|c|c|c|}
\hline \multirow[b]{2}{*}{ Interventio } & \multicolumn{2}{|c|}{ Perceived Relaxation (cm) } & \multicolumn{2}{|c|}{ Systolic Blood Pressure (mmHg) } & \multicolumn{2}{|c|}{$\begin{array}{l}\text { Diastolic Blood Pressure } \\
\qquad(\mathrm{mmHg})\end{array}$} & \multicolumn{2}{|c|}{ Heart Rate (bpm) } & \multicolumn{2}{|c|}{ Fingertip Temperature $(\stackrel{\circ}{ } \mathrm{C})$} \\
\hline & Mean & Difference $(95 \%$ & Mean & Difference $(95 \% \mathrm{Cl})$ & Mean & Difference $(95 \%$ & Mean & Difference $(95 \%$ & Mean & Difference $(95 \%$ \\
\hline$n$ & (SD) & $\mathrm{Cl})$ & (SD) & & (SD) & $\mathrm{Cl})$ & (SD) & $\mathrm{Cl})$ & (SD) & $\mathrm{Cl})$ \\
\hline GIM & & $2.54(1.92$ to & & $-2.59(-6.08$ to & & $-1.91(-4.61$ to & & $-1.70(-4.04$ to & & $1.80(0.13$ to \\
\hline Pre & 4.6 & $3.15)^{* *}$ & 110.8 & $0.89)$ & $70.5(8.8)$ & $0.79)$ & $70.7(9.8)$ & $0.64)$ & $28.4(4.4)$ & $3.47)^{*}$ \\
\hline Post & (1.9) & & $(8.7)$ & & $68.6(8.1)$ & & 69.0 & & $30.2(3.9)$ & \\
\hline & 7.1 & & 108.2 & & & & $(10.8)$ & & & \\
\hline & (1.9) & & $(8.3)$ & & & & & & & \\
\hline Music & & 2.34 (1.71 to & & $-4.10(-6.69$ to - & & $-0.98(-3.54$ to & & $-0.89(-3.31$ to & & 3.46 (1.68 to \\
\hline Pre & 5.7 & $2.97)^{* *}$ & 111.4 & $1.50)^{* *}$ & $71.0(9.5)$ & $1.57)$ & 70.5 & $1.53)$ & $27.0(3.7)$ & $5.24)^{* *}$ \\
\hline Post & $(1.5)$ & & (8.9) & & $70.0(8.3)$ & & (11.0) & & 30.5 (3.7) & \\
\hline & 8.0 & & 107.3 & & & & 69.6 & & & \\
\hline & $(1.3)$ & & (9.1) & & & & $(10.0)$ & & & \\
\hline $\mathrm{RL}$ & & 1.08 (0.54 to & & $-3.10(-6.40$ to & & $-2.68(-5.54$ to & & $0.20(-2.00$ to & & 2.31 (1.00 to \\
\hline Pre & 6.0 & $1.61)^{* *}$ & 111.3 & 0.19) & $73.2(7.7)$ & 0.19) & 70.7 & 2.39) & $28.1(4.6)$ & $3.62)^{* *}$ \\
\hline Post & $(1.3)$ & & $(8.1)$ & & 70.5 (8.5) & & (10.1) & & $30.4(3.6)$ & \\
\hline & 7.0 & & 108.2 & & & & 70.9 (9.7) & & & \\
\hline
\end{tabular}




$$
(1.7)
$$

\begin{tabular}{|c|c|c|c|c|c|c|c|c|c|c|}
\hline $\mathrm{GIM}+\mathrm{RL}$ & & 2.11 (1.50 to & & $-1.76(-4.53$ to & & $-1.00(-3.65$ to & & $-1.25(-3.25$ to & & 2.45 (0.51 to \\
\hline Pre & 5.7 & $2.72)^{* *}$ & 109.8 & $1.00)$ & $70.0(9.6)$ & 1.65) & $71.6(9.8)$ & $0.74)$ & $28.8(4.7)$ & $4.39)^{*}$ \\
\hline \multirow[t]{3}{*}{ Post } & (1.9) & & $(8.5)$ & & $69.0(8.0)$ & & $70.3(9.1)$ & & $31.2(4.1)$ & \\
\hline & 7.8 & & 108.1 & & & & & & & \\
\hline & $(1.3)$ & & (8.5) & & & & & & & \\
\hline Music + RL & & 2.04 ( 1.11 to & & $-1.41(-4.48$ to & & $0.60(-1.73$ to & & $-1.22(-3.51$ to & & 2.37 (0.73 to \\
\hline Pre & 5.1 & $2.96)^{* *}$ & 111.8 & 1.65) & 71.3 & 2.92) & 73.1 & $1.08)$ & $27.8(4.6)$ & $4.01)^{* *}$ \\
\hline \multirow[t]{3}{*}{ Post } & (1.9) & & (10.1) & & (10.3) & & (10.1) & & 30.2 (3.9) & \\
\hline & 7.1 & & 110.4 & & $71.9(8.7)$ & & $71.9(9.4)$ & & & \\
\hline & $(1.6)$ & & (9.7) & & & & & & & \\
\hline Control & & 1.02 (0.51 to & & $-0.84(-3.07$ to & & $-1.64(-4.77$ to & & $1.11(-0.77$ to & & 1.27 ( -0.16 to \\
\hline Pre & 5.8 & $1.52)^{* *}$ & 110.2 & $1.38)$ & $73.1(9.4)$ & 1.49) & 67.0 & 2.99) & $28.2(4.3)$ & 2.71) \\
\hline \multirow[t]{3}{*}{ Post } & $(1.3)$ & & (8.9) & & 71.5 & & (10.3) & & 29.5 (3.9) & \\
\hline & 6.8 & & 109.3 & & $(11.5)$ & & $68.1(9.7)$ & & & \\
\hline & $(1.4)$ & & (9.7) & & & & & & & \\
\hline
\end{tabular}

$2 * p<0.05, * * p<0.01 ;$ GIM: Guided-imagery Meditation, RL: Relaxation Lighting

3 


\section{Table 3(on next page)}

Mean differences in primary outcomes following each intervention compared to the control State

$* p<0.05 ; * *<<0.01$ 
1 Table 3. Mean Differences in Primary Outcomes Following Each Intervention Compared to the Control State

\begin{tabular}{|c|c|c|c|c|c|c|c|c|c|c|}
\hline \multirow[b]{2}{*}{ Intervention } & \multicolumn{2}{|c|}{$\begin{array}{l}\text { Perceived Relaxation } \\
(\mathrm{cm})\end{array}$} & \multicolumn{2}{|c|}{$\begin{array}{c}\text { Systolic Blood } \\
\text { Pressure (mmHg) }\end{array}$} & \multicolumn{2}{|c|}{$\begin{array}{l}\text { Diastolic Blood } \\
\text { Pressure (mmHg) }\end{array}$} & \multicolumn{2}{|c|}{ Heart Rate (bpm) } & \multicolumn{2}{|c|}{$\begin{array}{c}\text { Fingertip } \\
\text { Temperature }(\stackrel{\circ}{ } \mathrm{C})\end{array}$} \\
\hline & $\begin{array}{c}\text { Mean } \\
(\mathrm{SD})\end{array}$ & $\begin{array}{l}\text { Effect Size } \\
\text { (d) }\end{array}$ & $\begin{array}{c}\text { Mean } \\
(\mathrm{SD})\end{array}$ & $\begin{array}{l}\text { Effect Size } \\
\text { (d) }\end{array}$ & $\begin{array}{c}\text { Mean } \\
(\mathrm{SD})\end{array}$ & $\begin{array}{l}\text { Effect Size } \\
\text { (d) }\end{array}$ & $\begin{array}{c}\text { Mean } \\
(\mathrm{SD})\end{array}$ & $\begin{array}{l}\text { Effect Size } \\
\text { (d) }\end{array}$ & $\begin{array}{c}\text { Mean } \\
\text { (SD) }\end{array}$ & $\begin{array}{c}\text { Effect Size } \\
\text { (d) }\end{array}$ \\
\hline $\begin{array}{l}\text { GIM } \\
\text { Control }\end{array}$ & $\begin{array}{c}1.49 \\
(1.09)\end{array}$ & $1.4^{* *}$ & $\begin{array}{l}-1.78 \\
(9.03)\end{array}$ & -0.2 & $\begin{array}{l}-0.52 \\
(8.19)\end{array}$ & -0.06 & $\begin{array}{l}-3.15 \\
(4.57)\end{array}$ & $-0.7^{*}$ & $\begin{array}{c}0.50 \\
(2.84)\end{array}$ & 0.2 \\
\hline $\begin{array}{l}\text { Music } \\
\text { Control }\end{array}$ & $\begin{array}{c}1.26 \\
(1.23)\end{array}$ & $1.0^{* *}$ & $\begin{array}{l}-3.26 \\
(6.31)\end{array}$ & $-0.5^{*}$ & $\begin{array}{c}0.66 \\
(6.94)\end{array}$ & 0.1 & $\begin{array}{l}-2.00 \\
(6.23)\end{array}$ & -0.3 & $\begin{array}{c}2.19 \\
(3.06)\end{array}$ & $0.7^{* *}$ \\
\hline $\begin{array}{l}\mathrm{RL} \\
\text { Control }\end{array}$ & $\begin{array}{c}0.03 \\
(1.27)\end{array}$ & 0.02 & $\begin{array}{l}-2.29 \\
(6.00)\end{array}$ & -0.4 & $\begin{array}{l}-1.29 \\
(8.25)\end{array}$ & -0.2 & $\begin{array}{l}-1.25 \\
(5.82)\end{array}$ & -0.2 & $\begin{array}{c}1.01 \\
(3.90)\end{array}$ & 0.3 \\
\hline $\begin{array}{r}\mathrm{GIM}+\mathrm{RL} \\
\text { Control }\end{array}$ & $\begin{array}{c}1.09 \\
(1.53)\end{array}$ & $0.7^{* *}$ & $\begin{array}{l}-0.92 \\
(5.31)\end{array}$ & -0.2 & $\begin{array}{c}0.64 \\
(9.71)\end{array}$ & 0.1 & $\begin{array}{l}-2.36 \\
(5.88)\end{array}$ & -0.4 & $\begin{array}{c}1.18 \\
(3.05)\end{array}$ & 0.4 \\
\hline $\begin{array}{l}\text { Music + RL } \\
\text { Control }\end{array}$ & $\begin{array}{c}1.02 \\
(1.85)\end{array}$ & $0.6^{*}$ & $\begin{array}{l}-0.57 \\
(8.13)\end{array}$ & -0.1 & $\begin{array}{c}2.24 \\
(8.12)\end{array}$ & 0.3 & $\begin{array}{c}-2.32 \\
(6.42)\end{array}$ & -0.4 & $\begin{array}{c}1.10 \\
(4.22)\end{array}$ & 0.3 \\
\hline
\end{tabular}


Figure 1

CONSORT Flow Diagram for this within-subject trial.

Diagram shows participant flow through each stage of the trial (enrolment, allocation and analysis). One participant was unable to attend all the sessions and thus did not receive GIM nor RL. GIM: Guided-Imagery Meditation, ML: Music Listening, RL: Relaxation Lighting.

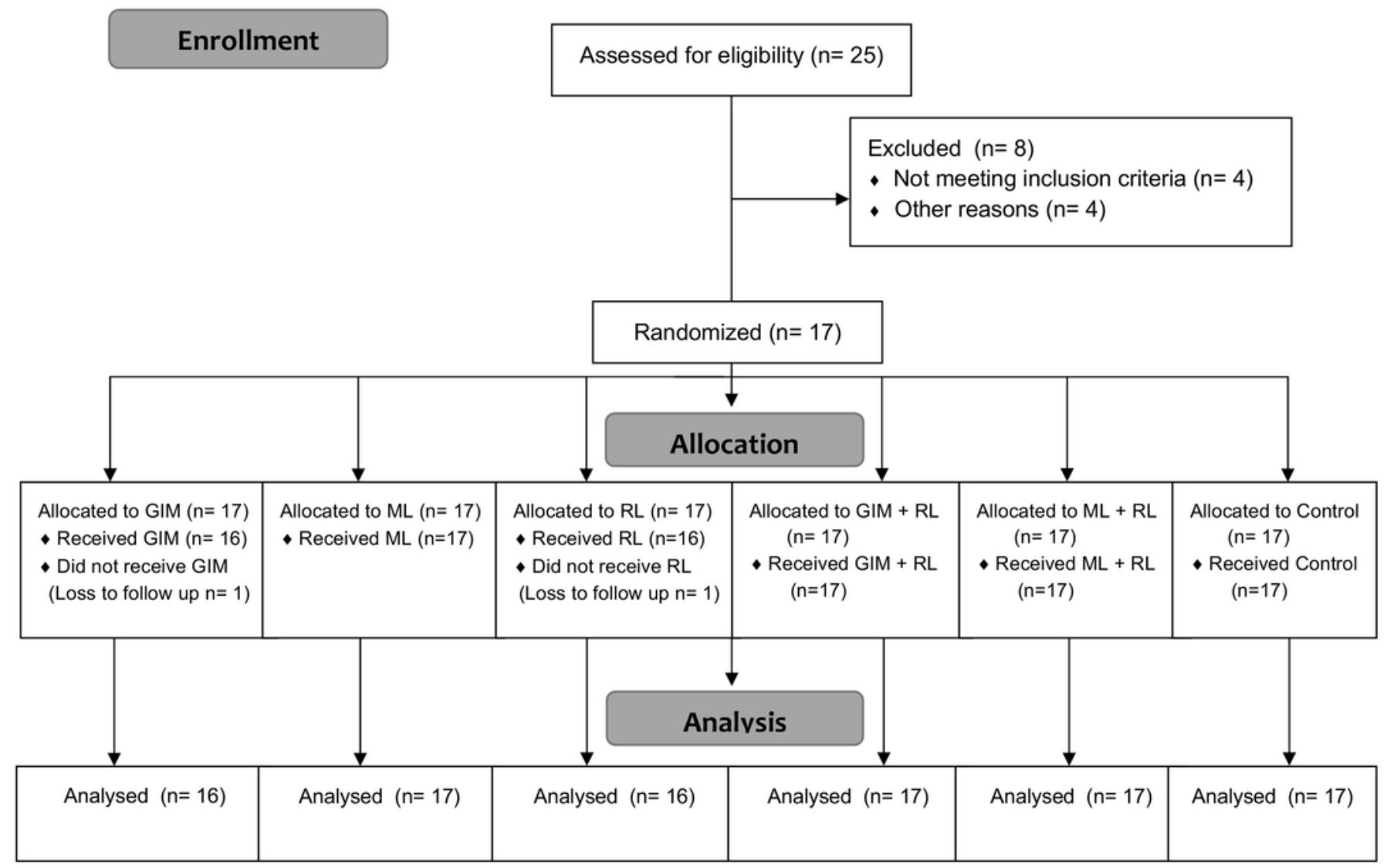


Figure 2

Mean changes in physiological relaxation measures: Systolic blood pressure (SBP; $\mathrm{mmHg}$ ), diastolic blood pressure (DBP; $\mathrm{mmHg}$ ), heart rate (HR; bpm), and fingertip temperature $(\mathrm{FT} ; \stackrel{\circ}{\circ} \mathrm{C})$.

Those significantly $(p<0.05)$ different from control were marked in asterisk $(*)$. Bars indicate SD values. GIM: Guided-Imagery Meditation, ML: Music Listening, RL: Relaxation Lighting

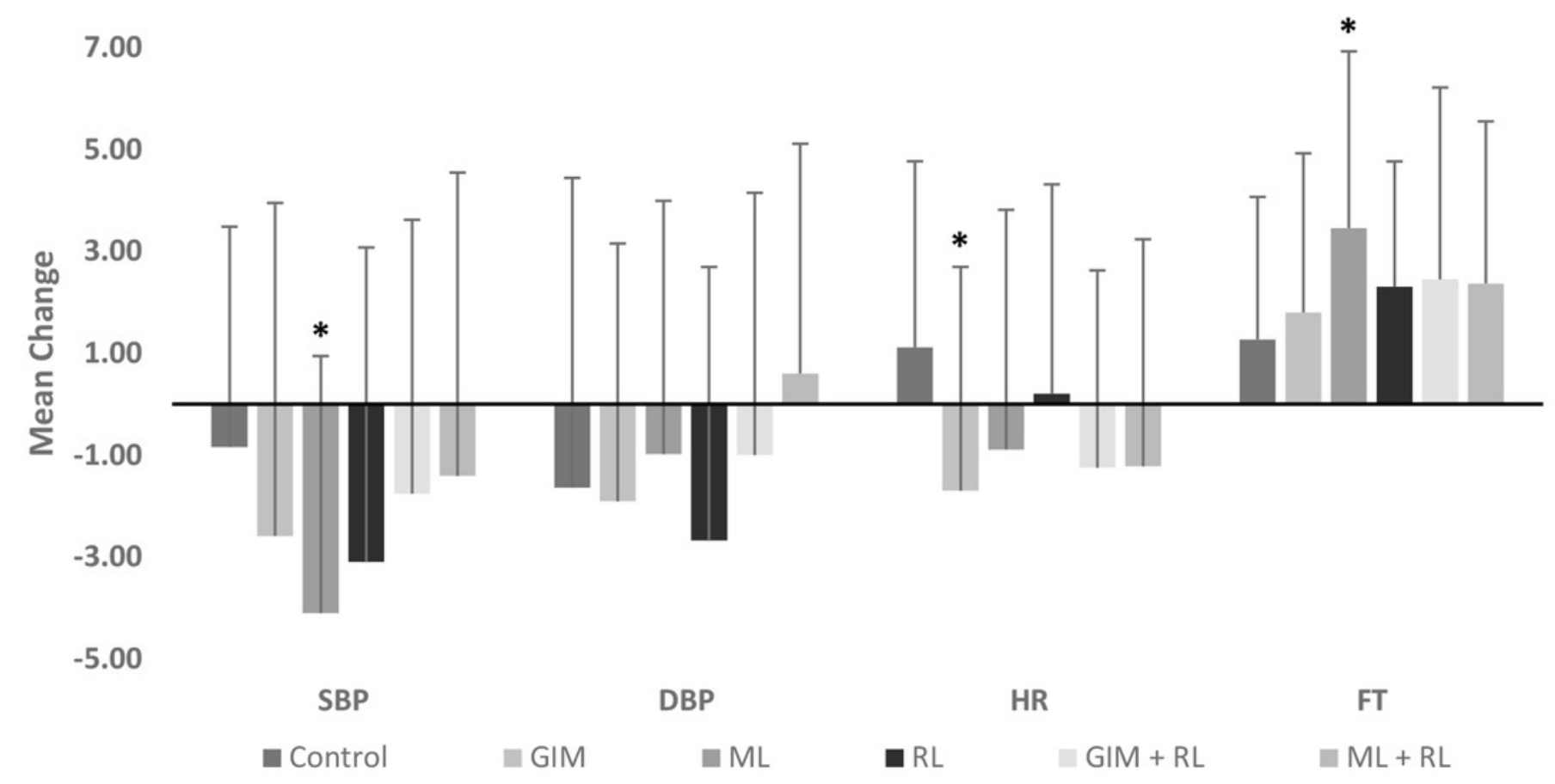




\section{Figure 3}

Mean changes in perceived relaxation (psychological measure) measured on a 10-point visual analogue scale.

Those significantly $(p<0.05)$ different from control were marked in asterisk (*). Bars indicate SD values. GIM: Guided-Imagery Meditation, ML: Music Listening, RL: Relaxation Lighting

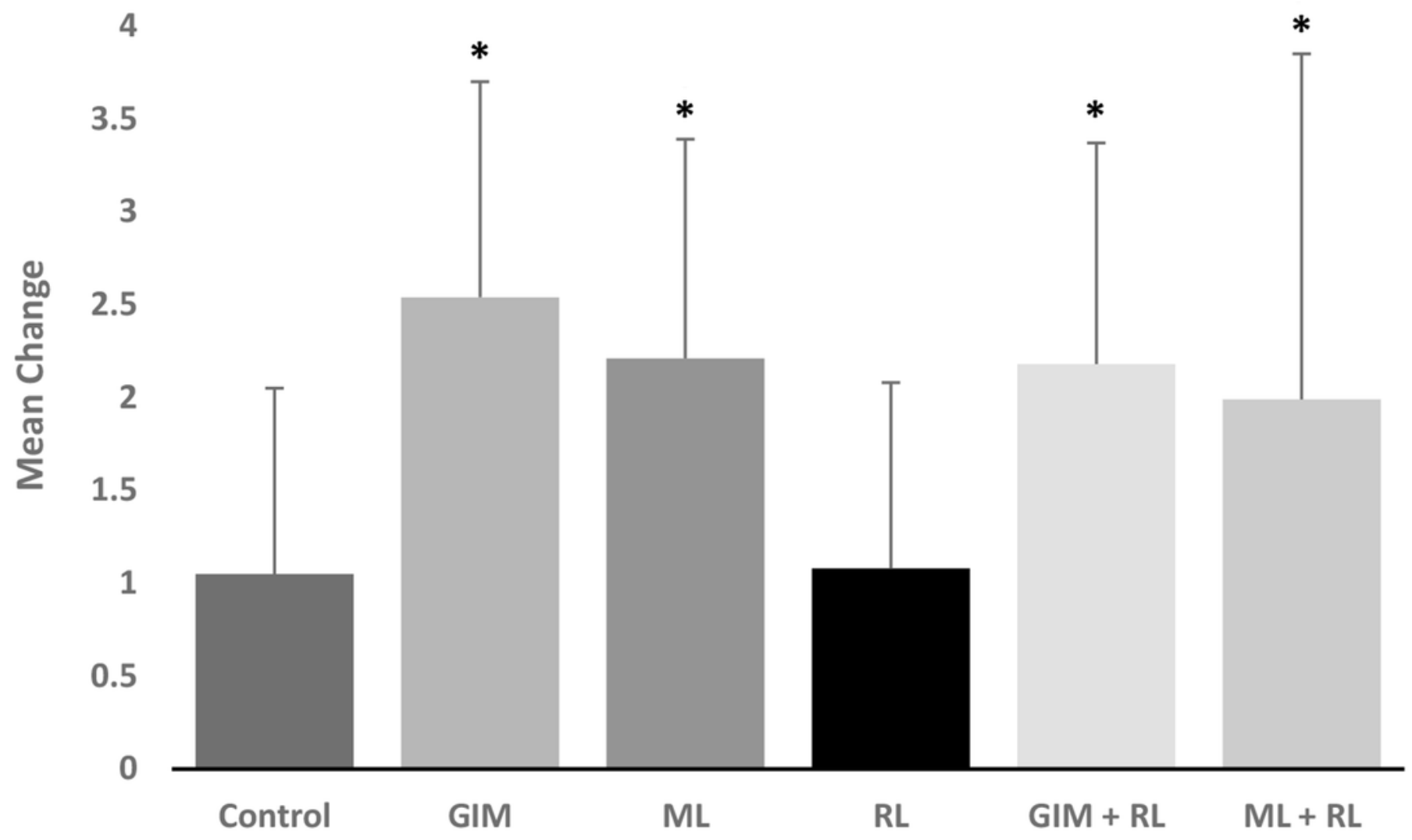

